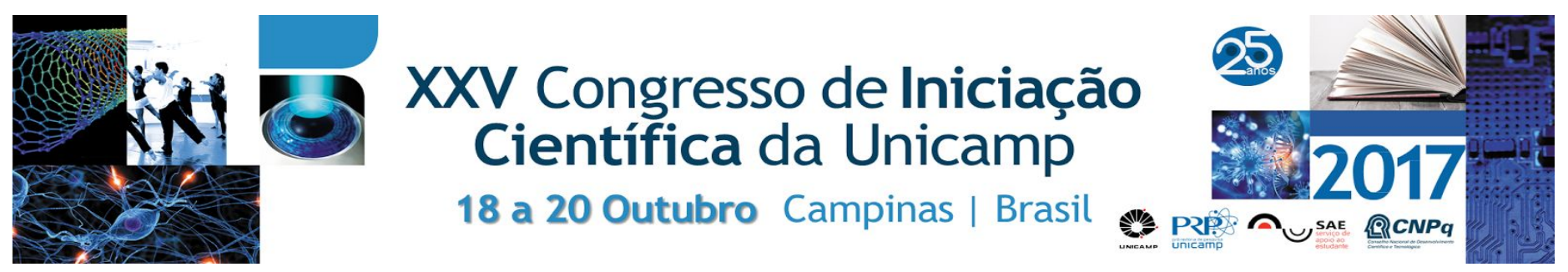

\title{
Determinação Experimental da Camada Limite Turbulenta Perturbada por uma Ruga
}

\section{Pedro Augusto Dalla Coletta*, Erick Moraes Franklin}

\section{Resumo}

Camadas limites turbulentas sobre paredes planas na presença de uma ruga são frequentemente encontradas na natureza e na indústria. A perturbação de uma camada limite bidimensional por uma ruga altera a maneira na qual as velocidades e as tensões são distribuídas ao longo do escoamento. Nos experimentos, escoamentos de água foram impostos sobre uma ruga afixada na parede inferior de um canal fechado e o campo de velocidades foi medido pela técnica PIV - Velocimetria por Imagem de Partículas. A partir das medidas instantâneas do escoamento, campos médios, tensores de Reynolds e energias médias e turbulentas foram calculados e comparados a expressões analíticas existentes na literatura.

\section{Palavras-chave:}

Camada limite turbulenta, Perturbação, ruga.

\section{Introdução}

Uma camada limite turbulenta perturbada por uma ondulação tem suas distribuições de velocidade e tensão alteradas. Neste projeto foi realizado o estudo experimental da perturbação de uma camada limite turbulenta perturbada por uma ruga bidimensional.

\section{Resultados e Discussão}

Com o tratamento de dados feito pelos alunos de doutorado e o de mestrado, é possível perceber que o perfil de velocidade do escoamento, Fig. 1, é assimétrico.

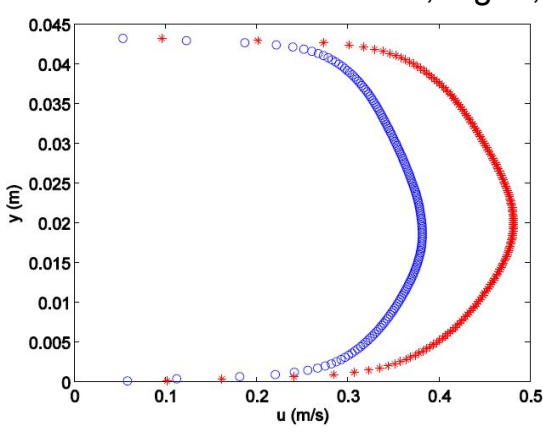

Figura 1. Perfil de velocidade do escoamento assimétrico na região não perturbada (Cuñez and Franklin, 2016).

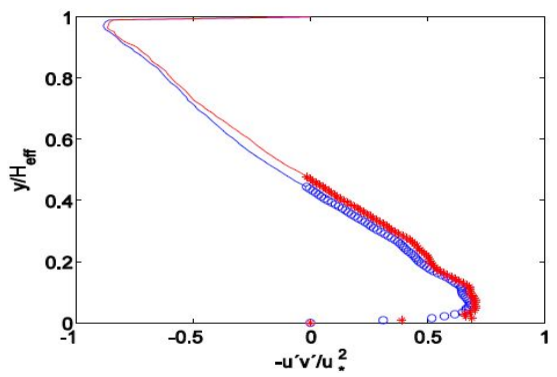

Figura 2. Deslocamento vertical versus Perfil da Tensão de Reynolds normalizada pela velocidade de atrito (Cuñez and Franklin, 2016).

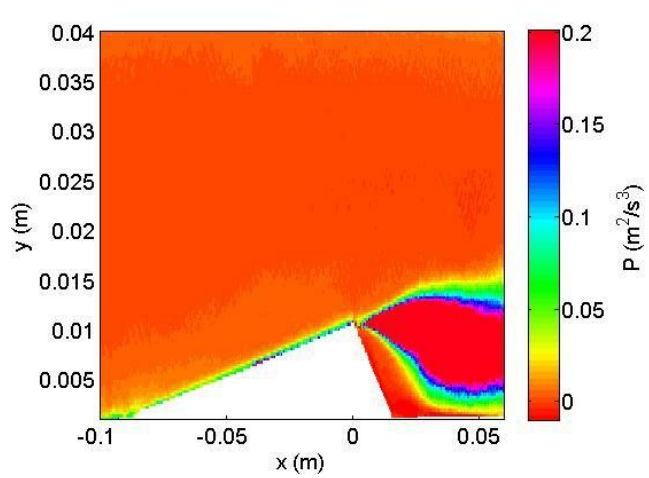

Figura 3. Produção de turbulência sobre a ruga (Cuñez and Franklin, 2016).

A assimetria na Fig. 1 se deve à diferença do material da parede superior (acrílico) e da parede inferior (PVC). A Fig. 2 apresenta o perfil de Reynolds na região não perturbada. A Fig. 3 apresenta a produção de turbulência para o escoamento perturbado.

\section{Conclusões}

Notou-se um perfil assimétrico do perfil de velocidade. Os campos de velocidades, tensões e produção de turbulência foram obtidos para o escoamento sobre a ruga.

Agradecimentos
Agradeço ao Conselho Nacional de

Desenvolvimento Científico e Tecnológico (CNPq) por todo o apoio e ao Professor Dr. Erick de Moraes Franklin.

Cuñez, F.D.; Franklin, E.M., Experiments on the perturbation of a channel flow by a triangular ripple. In: 18th International Symposia on Applications of Laser Techniques to Fluid Mechanics, Lisboa, Portugal, 2016, submitted. 